\title{
LOS AYMARAS DEL NORTE DE CHILE ENTRE LOS SIGLOS XIX Y XX. UN RECUENTO HISTÓRICO ${ }^{1}$
}

\author{
THE AYMARAS OF NORTHERN CHILE IN THE 19TH \\ AND 20TH CENTURIES. AN HISTORICAL ACCOUNT
}

\section{ALBERTO DÍAZ ARAYA ${ }^{2}$ MARCELA TAPIA LADINO3}

\section{RESUMEN}

El presente artículo tiene como finalidad sintetizar la historia aymara del norte chileno entre los siglos XIX y XX, en base a una revisión de la producción científica social e histórica desarrollada en el norte de Chile. El objetivo es sistematizar la historia regional aymara contemporánea en un texto para su difusión.

Palabras clave: Historia aymara, estados, chilenización.

\section{ABSTRACT}

This article offers a panorama of aymara history in northern Chile between the nineteenth and twentieth century, based on local sources and an analysis of recent historiographic documentation. The aim is to reconstruct contemporary Aymara regional history, sistematically, in an article aimed at a wide audience.

Keywords: Aymara history, states, chileanization.

Recibido: 04.06.12. Aceptado: 05.11.12.

${ }^{1}$ El primer autor agradece el apoyo de los Proyectos Fondecyt 1120530 y UTA No 5732-12. Además recibió el apoyo del Convenio de Desempeño Universidad de Tarapacá-Mineduc. El segundo autor contó con el apoyo del proyecto de Investigación Interno DI14-2004 de la Universidad Arturo Prat.

${ }^{2}$ Doctor en Antropología, Universidad de Tarapacá Departamento de Ciencias Históricas y Geográficas. Arica, Chile. Correo electrónico: albertodiaz@uta.cl

${ }^{3}$ Doctor en América Latina Contemporánea Universidad Arturo Prat, Instituto de Estudios Internacionales (INTE). Iquique, Chile. E-mail: marcela.tapia@unap.cl 
$\mathrm{P}$ ESQUISAR LA HISTORIA DE LOS AYMARA durante los siglos XIX y XX implica revisar la historia andina desde las distintas visiones ( $\mathrm{y}$ versiones) elaboradas tanto por la historiografía chilena como la peruana, matizadas por las acciones sociopolíticas de los estados que invisibilizaron a los segmentos indígenas de sus relatos. Así, acontecimientos como la incorporación de comuneros andinos al modelo económico de exportación de guano y salitre desde mediados del siglo XIX, los programas de "chilenización" en los albores del 1900, los efectos de la escuela fiscal, los procesos migratorios, entre otros, han sido los principales hitos y temas de preocupación de los investigadores/as para develar la experiencia histórica de los aymaras del actual norte de Chile, que antes habitaron en territorio peruano y boliviano respectivamente (González, 2002a; Díaz, Galdames y Ruz, 2010).

Teniendo en cuenta las complejidades que supone reconstituir el pasado reciente de los indígenas andinos, proponemos realizar un recuento de su historia poscolonial que nos permita identificar su protagonismo como agentes en la construcción de su devenir. Para ello, nos detendremos en el periodo que arranca a fines del siglo XIX hasta la primera mitad del siglo $\mathrm{XX}$, puesto que se trata de uno de los periodos de mayor preocupación disciplinaria, dadas sus múltiples repercusiones a nivel regional como del área Centro Sur Andina.

\section{INDÍGENAS Y ESTADO NACIÓN}

A inicios del siglo XIX los procesos independentistas hispanoamericanos cambiaron el rostro a la América colonial. Nacen numerosos estados, la mayoría de ellos utilizando las divisiones administrativas coloniales, cuyas fronteras no fueron precisadas por los líderes de la emancipación. Estas repúblicas contaron con un número no menor de étnicos, siendo Ecuador, Perú y Bolivia los países que concentraron más del 50\% del total de la población indígena. Contraria a la tesis de la expoliación de los comuneros andinos, ésta experimentó un importante crecimiento durante el siglo XIX (Díaz, Ruz y Galdames, 2011). Entre las razones que ayudan a entender tal fenómeno, estaba la necesidad de usufructuar de la contribución indígena que alimentaba buena parte del fisco de las emergentes repúblicas en los 
Andes. Al respecto, el detalle del peso demográfico de los indígenas se constata en el siguiente cuadro:

Cuadro 1. Población indígena estimada y su peso demográfico por país entre 17901920.

\begin{tabular}{|l|c|c|c|c|}
\hline \multirow{2}{*}{ País Andino } & \multicolumn{2}{|c|}{ Hacia $1790-1830$} & \multicolumn{2}{c|}{ Hacia 1870-1920 } \\
\cline { 2 - 5 } & $\begin{array}{c}\text { No estimado } \\
\text { indígenas }\end{array}$ & $\begin{array}{c}\% \\
\text { población }\end{array}$ & $\begin{array}{c}\text { No estimado de la } \\
\text { población nacional }\end{array}$ & $\begin{array}{c}\% \\
\text { indígenas }\end{array}$ \\
\hline Venezuela & 120.000 & 6 & 59.016 & 3.3 \\
\hline Colombia & 313.000 & 22.3 & 158.000 & 2.6 \\
\hline Ecuador & 393.000 & 65.5 & 662.400 & 50.6 \\
\hline Perú & 934.814 & 61.6 & 1.562 .910 & 57.9 \\
\hline Bolivia & 474.866 & s/d & 906.126 & 54 \\
\hline Chile & 200.000 & s/d & 101.118 & 3.1 \\
\hline
\end{tabular}

Fuente: Thurner (2003).

Ya instaladas las nuevas repúblicas fue necesario aclarar la situación de los indígenas en tanto a su condición de ciudadanos. Bajo el influjo del modelo liberal que alimentó a los independentistas, no deberían existir indios, sólo ciudadanos en un contexto de igualdad sociopolítica. No obstante, la realidad de la América andina dictaba lo contrario, ya que la presencia de los "indios" contrariaba la consolidación de las incipientes repúblicas (Thurner, 2003: 176). Tempranamente el libertador San Martín intentó contrarrestar el principio de la desgracia política de los grupos de indios, para lo cual abolió la denominación de "indios o naturales" junto con el "tributo indigenal", ya que eran expresiones del "despotismo" hispano, remanentes de la antigua institucionalidad colonial (Walker, 1999). Sin embargo, aquellas disposiciones tributarias ciertamente generaron inestabilidad económica en la naciente república peruana (Thurner, 2003).

Por otra parte, fiel a las ideas liberales, Simón Bolívar acuñó la expresión afrancesada de "indígenas" para designar a los "indios" y reemplazar la denominación de "peruanos". Bolívar, en los decretos de 1824 y 1825, confirmó la abolición del tributo indígena, suprimió la propiedad corporativa sobre las tierras de los indígenas y los títulos de nobiliarios (ej. caciques), agregando, la eliminación de las faenas, séptimas, mitas y/o pongos; en definitiva, todos los servicios personales gratuitos que pervivían desde la época colonial. Dicho sea de paso, la abolición de la propiedad comunitaria 
fue rápidamente modificada, ya que se temió que sirviera sólo para convalidar futuros despojos de tierras indígenas. Estas disposiciones requerían que sólo los indígenas alfabetizados podrían ejercer derecho sobre sus tierras (Díaz, Ruz y Galdames, 2011).

Debido a la falta de organización en la fragmentación de los territorios comunales y al desinterés de los propios indígenas, éstas medidas carecieron de efectos prácticos. Con sus respectivos matices, el escenario legal de las propiedades comunitarias permaneció en un verdadero "limbo", debido a que en aquellos conflictos que no fueran contrarios a la legislación republicana regirían las antiguas "Leyes de Indias". Como a los burócratas peruanos poco les interesaba la situación política de los indígenas, en algunos casos quedaron definitivamente ligados al orden jurídico colonial como un estatuto de "costumbres ancestrales" (Contreras y Cueto, 2000: 69).

Pese a que las medidas bolivarianas buscaron integrar a la nación peruana al componente indígena andino, en la práctica se conservaron las viejas estructuras tributarias coloniales. En este tablado, la economía peruana no podía sostenerse por sí sola, lo que gravitó una crisis económica en las arcas fiscales; crisis que fue revertida en 1826 por Hipólito Unanue al restablecer la "contribución correspondiente a los indígenas". Tales disposiciones recayeron sobre los indígenas para financiar en parte la economía nacional, estableciéndose una suerte de "ciudadanía tributaria" republicana (Thurner, 2003; Contreras y Cueto, 2000).

Para la década de 1830 se exigieron demandas para eliminar los trabajos forzados y la servidumbre de los indígenas; dictámenes que los gobiernos liberales fueron implementando muy lentamente. No obstante, algunos sectores conservadores manifestaron su interés porque los indígenas no enajenaran sus tierras, buscando mantener el sistema de mita (turnos en faenas) o el servicio personal. Un balance de la contribución indígenal en Perú y Bolivia para mediados del XIX se puede ver en el siguiente cuadro.

\footnotetext{
${ }^{4}$ La Constitución peruana de 1826, conocida como "la vitalicia", fue mucho más rígida que los reglamentos decretados por San Martín o Bolívar. Esta excluyó de la condición ciudadana no sólo a los que realizaban trabajos domésticos o servidores manuales, sino que directamente a la población analfabeta, como corresponde al caso de los indígenas, ya que actualizó los anteriores requisitos sobre lecto-escritura que en 1823 habían sido postergados en su aplicación para el ejercicio de los derechos ciudadanos. Esta Constitución era incompatible con la regulación de las igualdades jurídicas en Perú. Un estudio jurídico mucho más detallado ha sido formulado por Débora Urquieta (1993).
} 
Cuadro 2. La contribución indígena en las repúblicas andinas.

\begin{tabular}{|c|c|c|c|c|}
\hline Año & \multicolumn{2}{|c|}{ Perú } & \multicolumn{2}{c|}{ Bolivia } \\
\hline & $\begin{array}{c}\text { Cont. est. miles de } \\
\text { pesos nacionales }\end{array}$ & $\begin{array}{c}\text { \% del total de las } \\
\text { rentas fiscales }\end{array}$ & $\begin{array}{c}\text { Cont. est. miles de } \\
\text { pesos nacionales }\end{array}$ & $\begin{array}{c}\text { \% del total de las } \\
\text { rentas fiscales }\end{array}$ \\
\hline 1830 & 945 & 12 & 718 & 47 \\
\hline 1835 & -- & -- & 678 & 39 \\
\hline 1840 & 1757 & 39 & 745 & 45 \\
\hline 1845 & -- & -- & 823 & 36 \\
\hline 1850 & -- & -- & 919 & -- \\
\hline 1855 & 1039 & -- & 883 & 38 \\
\hline 1860 & -- & -- & 650 & 37 \\
\hline & & & 693 & 41 \\
\hline & & & 340 & 20 \\
\hline & & & 724 & 25 \\
\hline
\end{tabular}

Fuente: Thurner 2003.

El aporte de los indígenas a las arcas del fisco peruano en este periodo ascendió al 40\%. Para el caso de Tarapacá, González (2002), sobre la base del padrón de contribuyentes del año 1845 , sostiene que la contribución indígena representó $82,5 \%$ del total de ingresos fiscales. Como lo ha descrito Dueñas (2005), en los ayllus de Tacna hubo situaciones que implicaron conflictos entre los comisarios que debían realizar los cobros y los indígenas contribuyentes, llegando incluso a juicios entre las partes involucradas hacia 1835. La contribución indígena también significó un universo de relaciones y discursos contradictorios entre el Estado y los indígenas, debido a que operaron articulaciones en base a viejas matrices coloniales. $\mathrm{Al}$ respecto, Walker (1999) plantea que en tal contexto social significó abrir campos de negociación entre el Estado y las poblaciones indígenas de Perú hacia la medianía del siglo XIX.

En perspectiva, la posición de los indígenas al interior de la sociedad peruana decimonónica fue ambigua, ya que se desplazaba contradictoriamente entre un status de sujeto tributario (remanente de los vestigios coloniales) al de un ciudadano propietario (libre, con múltiples derechos). Esta ambigüedad discursiva (moderna y ciudadana) y práctica (praxis colonial), tanto en contenidos sociales como políticos, caracterizó las relaciones (en ocasiones tensas) entre los comuneros andinos y el Estado, generando la mentada "ciudadanía tributaria" (Contreras y Cueto, 2000).

La persistencia de las estructuras virreinales en un formato político liberal respondió a una hibridez social y política, contexto que permitió a los indígenas apelar a la condición de ciudadanía para sostener demandas por educación y/o protección legal de parte del Estado, y al mismo tiempo, al 
utilizar la condición de contribuyentes, articular el reconocimiento estatal de los viejos títulos coloniales sobre repartimientos. Esta figura sociopolítica de complejas relaciones entre el Estado y los segmentos indígenas pervivió hasta el 5 de julio de 1854, fecha en la que Ramón Castilla, originario de Tarapacá, abolió definitivamente la contribución indígenal, gracias a la bonanza económica generada por la explotación del guano, que aumentó las arcas fiscales peruanas, inhibiendo la participación de los indígenas (Bonilla, 1988).

La abolición de la contribución indígena también puede ser considerada como ambigua y compleja según los escenarios históricos, territoriales y étnicos. En algunos lugares (y periodos) se aplicó la cancelación de impuestos sobre la persona o la propiedad, con deficientes resultados para las comunidades. Asimismo, la abolición permitió que se generara protagonismo comunitario en el ejercicio de poder a nivel local, como fueron las figuras de los cuadillos o los gamonales (Aljovín de Losada, 1997; Sala i Vila, 1996).

Años más tarde, para 1876 una resolución Suprema se pronunció en favor de los indígenas como "sujetos libres", los cuales podían decidir sobre la distribución de sus tierras, sin la intervención de las autoridades (Gundermann, 2001). Con tales antecedentes, es posible suponer que la tributación al fisco peruano se implementó en forma regular en el sur peruano (incluidos Arica y Tarapacá), territorio donde paulatinamente las poblaciones indígenas se fueron insertando como actores dinámicos en su relación con el Estado, bajo la calidad política de "ciudadanos tributarios".

En esta época, las comunidades andinas del actual norte chileno se vincularon con los mercados regionales que hacían sentir sus actividades en la zona, como ya lo había sido el mineral de Huantajaya. Desde mediados del siglo XIX la industria del guano en la costa y la naciente actividad salitrera del cordón pampino que iba desde Zapiga por el norte hasta la oficina Mapocho por el sur, fueron espacios económicos aprovechados tanto para abastecer con productos agrícolas a las oficinas o aportar con mano de obra local a dicha actividad industrial (Gundermann, 2001).

En un plano simbólico, los grupos indígenas aymaras asumieron los signos de la identidad peruana no sólo en el plano sociopolítico, sino que además en los rituales y festividades, con cintas de rojo y blanco para los estandartes del alférez, el izamiento del pabellón patrio o el cántico del himno cada 28 de julio. Estas manifestaciones expresaban simbólicamente la pertenencia a la identidad nacional, y que en algunos casos se acentuaron con la ocupación de las tropas chilenas en la región (Galdames y Díaz, 2007).

Así, el camino recorrido por las comunidades andinas durante el siglo 
XIX se circunscribe a diversas modalidades de prácticas sociales e identitarias, donde la heterogeneidad de las situaciones políticas y culturales dieron cuenta de las diversas formas para responder al proyecto liberal y republicano, asumiendo en muchos casos un carácter contradictorio, tanto en la incorporación de las regalías fundadas en la ciudadanía como en la apelación al viejo discurso colonial en el que se reconocían sus derechos y costumbres sobre las tierras.

En síntesis, las comunidades andinas articularon una praxis política intermedia -entre el Estado y la comunidad-, que supuso ciertos "acomodos" o negociaciones en muchos casos en direcciones contradictorias. Para el caso nortino, es posible advertir que el escenario híbrido entre los indígenas y Estado operó bajo un formato de "larga duración" durante la incorporación de los territorios a la soberanía chilena. En este tejido sociohistórico, el siglo XIX dio cuenta de notables transformaciones identitarias al interior de las comunidades andinas, generándose desde una rotulación virreinal como "indios", pasando por la expresión de "peruanos", la cual paulatinamente fue reemplazada por la denominación de "chilenos" con la arremetida del siglo XX (Gundermann, 2005).

\section{LOS AYMARAS Y EL ESTADO CHILENO}

La Guerra del Pacífico fue un hito trascendental para la configuración del espacio y la historia regional nortina. El establecimiento de nuevos límites y la anexión de territorios ricos en minerales convirtieron la antigua provincia boliviana de Antofagasta y las peruanas de Arica y Tarapacá, en una zona estratégica para el desarrollo económico del país. En el caso de Tarapacá, la anexión quedó formalizada por el Tratado de Ancón de 1883, por el cual la provincia quedó bajo soberanía chilena pero dejaba a la Provincia de Tacna y Arica bajo administración chilena sujeta a un plebiscito que resolvería su situación. Dicho plebiscito no se realizó en el plazo estipulado (1894), situación que llevó al gobierno peruano a impugnar el tratado de 1883 y a reclamar a las provincias "cautivas" (Galdames y Díaz, 2007). Esta situación se zanjó en 1929 con el Tratado de Lima, sin embargo el litigio dejó abierta la compuerta para un problema mayor: la violencia nacionalista y xenófoba en contra de la población peruana tarapaqueña (González 2004).

Durante este periodo hasta la crisis del ciclo salitrero (1930) se pueden distinguir algunos hechos de interés histórico-regional, como son la incorporación de nuevos territorios, la nueva organización de éste bajo el Estado 
chileno, la expansión del ciclo salitrero, el crecimiento poblacional, el origen del movimiento obrero y la política de asimilación de las comunidades indígenas aymara a través de la escuela fiscal y el reclutamiento militar y el proceso de "chilenización". Sobre este último aspecto, Gundermann advierte que 1907 se reconstituye como

un año de traumática experiencia de irrupción represiva estatal sobre el mundo obrero regional, que el Estado chileno empieza a materializar una verdadera soberanía sobre la región. Se desarrolla la escuela fiscal, se instaura el servicio militar obligatorio, se crean la 'ligas patrióticas', las autoridades dependen financieramente del fisco, se da una presencia militar más activa, la trinacionalidad característica de la población obrera durante el periodo empieza rápidamente a disminuir y las expresiones culturales de extracciones nacionales distintas (Gundermann, 2001: 152).

En términos analíticos, 1907 reconfigura la historia regional en un antes y un después, puesto que a partir de la masacre de obreros en la escuela Santa María de Iquique, se inaugura un doble proceso sociopolítico: por una parte, la represión sobre la población extranjera, especialmente la de origen peruano, y por otro, un proyecto civilizador e integrador de las comunidades andinas de la zona. Para González (2006), el proceso que afectó a la población peruana tiene como hito el año 1910, fecha que marcó el inicio de la chilenización compulsiva en la región. Este suceso fue el resultado de una serie de acontecimientos previos, entre los que se cuentan: el traslado de la Corte de Apelaciones desde Iquique a Tacna, la creación del Vicariato Castrense en Tacna y la expulsión de los curas peruanos en 1910. Asimismo, la chilenización y desperuanización compulsiva se artículo por oposición a los preceptos diplomáticos impulsados por la llegada de Augusto B. Leguía a la Presidencia de Perú. Durante el gobierno de Leguía se introdujo la reivindicación peruana por Tarapacá como la tercera provincia cautiva, además de Tacna y Arica, y la impugnación del Tratado de Ancón en su totalidad. De esta forma, el fenómeno de nacionalismo exacerbado y xenofobia se promovió de uno y otro lado de la frontera por los propios estados, alcanzando su mayor expresión -para el caso chileno- en los hechos de violencia física promovidos por las Ligas Patrióticas y la expulsión de peruanos tarapaqueños de sus casas y propiedades (González, 2004). 


\section{LA SOBERANÍA CHILENA}

Una vez producida la ocupación militar de Tarapacá (1879), rápidamente se reorganizó la actividad económica, política y administrativa de la zona. Se pusieron en vigencia las leyes chilenas y la división administrativa de Tarapacá fue asumida por la jefatura de Patricio Lynch. En 1886 se instalaron los Registros de Conservadores de Bienes Raíces con el objetivo de organizar legalmente la propiedad minera, como el establecimiento de las escuelas fiscales, principal agencia reproductora de la identidad y cultura nacional chilena (Díaz y Ruz, 2009; González, 2002a).

Con el paso de los años, las comunidades aymaras, así como toda la población tarapaqueña, debieron elaborar una nueva relación con el Estado, ahora como "nuevos chilenos". Los aspectos centrales de esta relación fueron, al parecer, la adscripción a la ciudadanía chilena y la participación en la estructura administrativa chilena a través de la inscripción de sus propiedades, ingreso en las escuelas y el reclutamiento militar (Díaz, 2009). En 1887 se decretó la Ley de adscripción a la nacionalidad peruana o chilena para toda la población tarapaqueña. Se otorgó un plazo de cuatro meses para que las personas nacidas antes de 1884 en este territorio declarasen la nacionalidad peruana.

En esta relación, la inscripción de la propiedad de la tierra en el Conservador de Bienes Raíces de Pisagua e Iquique fue otro elemento de vinculación al Estado de Chile. Los aymaras en los albores del siglo XX regularizaron sus propiedades de los valles y el altiplano, no teniendo mayores problemas para bajar hasta Pisagua a inscribir sus tierras (Gundermann, 2005). Del mismo modo, González (2002a) argumenta que los indígenas tarapaqueños tenían experiencia al respecto, tanto que no pocas veces inscribieron algunas tierras que correspondían a comunidades vecinas, originando con ello uno de los principales focos de conflicto intercomunitarios en la actualidad.

En relación a la instrucción pública, la escuela tuvo por objeto llevar a cabo una política de homogeneización cultural, lingüística e ideológica. Sin embargo, a diferencia de lo que han sostenido algunas interpretaciones desintegracionistas (como la propuesta por Van Kessel, 1992), los aymaras fueron proactivos a la instalación de escuelas en sus comunidades, debido a que 
la relación del aymara andino con la sociedad chilena a través de la escuela y la importancia que ellos le daban al proceso educativo, se caracterizó por las iniciativas de los campesinos para presionar al Estado a instalar escuelas en sus comunidades: se trataba de la cesión de un terreno y de una vivienda (a veces construida para ese fin específico) de propiedad de la comunidad a la Dirección Provincial de Educación (González 2002a: 23).

La acción de la escuela fiscal fue eficaz, ya que buscó la homogeneización cultural, lingüística e institucional de las comunidades aymaras y la imposición de la ideología occidental. El impacto de esta acción se prolongó hasta fines del siglo XX, cuando se promulgó la Ley indígena que reconoció la existencia de los pueblos originarios y sus derechos como etnia.

\section{LOS AYMARAS Y EL CICLO SALITRERO}

Un capítulo aparte en la historia regional lo constituye el ciclo salitrero, cuya expansión se registró desde la incorporación de Tarapacá a Chile hasta las primeras décadas del siglo XX. La explotación del salitre significó el ingreso definitivo de Chile al comercio mundial luego de la experiencia previa del trigo y la plata. Al mismo tiempo, esta actividad originó una sociedad multinacional, formada por sudamericanos, europeos y asiáticos, aunque escasamente se ha consignado la presencia de trabajadores de origen aymara o quechua en la configuración de la sociedad pampina multicultural (González, 2002b).

En el caso de los trabajadores de la pampa, la identidad obrera subsumió las diferencias étnicas, predominando por sobre todo la identidad de clase, y por añadidura la nacional, además del brote nacionalista. Sin embargo, debajo de esa pátina obrera y nacional quedó invisibilizada la presencia indígena que, sin embargo, se manifestó en algunas festividades pampinas como el Carnaval, la Cruz de mayo y la Fiesta de la Virgen del Carmen de La Tirana (Díaz, 2009).

Para el estudio del ciclo salitrero y su relación con las comunidades aymaras es preciso distinguir el espacio geográfico en la que se desarrolló esta actividad. La explotación salitrera comprendió básicamente la Provincia del Tamarugal en la Región de Tarapacá y Antofagasta, II Región. Sin embargo, también hubo una actividad significativa en la zona de Arica asociada al arrieraje que conectó el puerto ariqueño con Bolivia desde tiempos coloniales hasta avanzado el siglo XIX (Galdames y Díaz, 2007). Dichos 
espacios andinos fueron denominados por Sergio González (2002c), como espacio "interior" y "exterior". El primero incluyó los valles de Tarapacá y el segundo, "penetró hasta el noroeste argentino y por Bolivia, desde Oruro a Cochabamba... También llegó a los bofedales andinos la presencia cultural del mundo del nitrato" (González, 2002c: 260). De acuerdo a lo anterior, la denominada economía de enclave estuvo inserta en un espacio regional y subregional mayor, donde confluyeron activos flujos provenientes del sur de Perú (Arequipa), con mano de obra y diversas mercancías que llegaron por la vía del arrieraje e incluso por vía marítima. Desde el noroeste argentino se trajeron animales a pie y desde el altiplano boliviano y Cochabamba, se trajo charqui y hoja de coca. Asimismo, los circuitos nacionales se activaron por la vía de la zona central de Chile que proveyó de mano de obra (enganche), alimentos (cereales, azúcar, fideos) y una variedad de mercancías (carbón, vinos, cristales, paños, loza, cemento, zapatos, tabaco, etc.). Todo ello dio origen a una activa activad económica con un impacto no sólo regional, sino también nacional e internacional.

Por otra parte, la explotación del salitre se caracterizó por una alta concentración de la propiedad salitral en manos de extranjeros, una fuerte dependencia de la economía sobre este mineral y la rápida concentración de mano de obra en la pampa tarapaqueña y en la costa desértica. En este contexto, la población aymara participó activamente del auge salitrero configurando una economía regional cuya experiencia anterior se remontaba a la explotación del cerro rico de Potosí y más tarde del mineral de Huantajaya. De esta forma, las comunidades aymara se integraron a la economía del nitrato, básicamente de dos formas, como proveedores de alimentos y forrajes, y como mano de obra en las oficinas salitreras. De esta manera, se activaron diversos flujos comerciales que atravesaron el territorio desde el altiplano hasta la costa y viceversa, dando origen a nuevos agentes comerciales que desplazaron a los tradicionales. En el primer caso, los productos tradicionales de camélidos del altiplano "siguieron llevando a los valles su carne, su charqui, su quínoa, etc., pero los valles comenzaron a intercambiar productos venidos del puerto, arroz, azúcar, cigarros, utensilios domésticos etc, y pagar con dinero" (González, 2002c: 263), así el llamero tradicional, fue lentamente desplazado por el arriero en los circuitos del espacio interior.

En relación a la importancia de los valles precordilleranos, éstos se transformaron en ejes de comercialización que unieron los distintos pisos ecológicos, como el altiplano, los valles, la pampa y la costa. En un radio que va desde Codpa hasta Guatacondo, todas las comunidades participaron en la industria salitrera, no solamente como mano de obra asalariada, en 
una suerte de tránsito entre campesino y obrero; sino que las actividades cotidianas agrícolas cambiaron para potenciar los cultivos de mayor demanda de la industria, entre ellos la alfalfa, utilizada para la engorda del ganado vacuno, mular y caballar (Gundermann, 2001).

Por ejemplo, la localidad precordillerana de Chiapa se constituyó como un lugar obligado para el intercambio de diversas mercancías entre el altiplano y las oficinas salitreras, "fue una verdadera factoría al servicio de las salitreras, cuya finalidad era la conquista de un espacio y un mercado necesario para la explotación salitrera, mientras el hermoso valle y sus terrazas eran invadidas por el color de los alfalfares" (González, 2002: 266). De igual forma, el poblado de Tarapacá orientó su actividad triguera y molinera hacia las oficinas salitreras y agregó la producción de alfalfa para forraje. El valle de Camiña participó del ciclo salitrero enviando a sus hijos a trabajar en las oficinas salitreras, especialmente como empleados, costreros, jefes de pulpería y jefes de pampa, entre otros oficios. Sibaya, cabecera de valle y antigua doctrina colonial, se especializó en la producción de alfalfa para forraje, necesario para alimentar a los mulares y ganado en general (Díaz, 2003). El oasis de Pica tuvo un rol fundamental en las rutas del arrieraje, a diferencia de los valles antes mencionados, Pica contaba con una población básicamente blanca y mestiza. Por allí pasaban las caravanas provenientes de Argentina y Bolivia, para luego alcanzar las oficinas salitreras de la pampa.

Los ganaderos aymaras del altiplano potenciaron su actividad productiva como arrieros, abasteciendo de charqui y quinoa a las oficinas, permitiendo un mercadeo con redes que iban desde las zonas altas hasta las quebradas tributarias de la pampa del Tamarugal. También se demandó ante el Estado chileno la construcción de caminos y escuelas, por lo que el acceso a la educación como señaláramos más arriba poseía ribetes comunitarios (González, 2002a).

En las oficinas salitreras como Quirima, San José, Jazpampa, Rosario, Mapocho, entre otras, numerosos aymaras trabajaron como "particulares" (extracción de salitre sin un contrato previo) o como obreros pertenecientes a alguna empresa. Participaron en las huelgas y en la pampa reestablecieron sus festividades patronales, además de celebrar la fiesta de la Cruz de Mayo, la fiesta de La Tirana, el carnaval; organizaron bailes religiosos y comparsas de músicos. Incluso, cada año, volvían a sus pueblos de origen para la fiesta patronal, manteniendo la comunidad y los lazos culturales como de parentesco (Díaz, 2009).

El mercado regional salitrero sin duda integró a los aymaras y éstos participaron en él; de hecho, los mayores adelantos en las comunidades 
en términos arquitectónicos y el periodo más recordado por la población andina lo constituye el cenit del ciclo salitrero. Por su parte, los aymaras introdujeron diversos topónimos y costumbres amplificando el glosario de la actividad productiva calichera; uno de ellos era mascar coca durante las labores extractivas del nitrato. La participación de la población indígena en la industria salitrera y los mercados regionales no supuso el fin de la historia de la comunidad, sino que, por el contrario, se trató de un periodo de fuerte intercambio cultural, que significó la adopción de nuevos hábitos y pérdida de otros.

Con la decadencia de la industria del salitre se produjo gradualmente un importante desplazamiento de población pampina hacia los puertos del litoral nortino. Arica, que para 1953 organizaba el Puerto Libre y posterior a éste la zona Industrial potenciada por la Junta de Adelanto fue un foco atractivo e interesante para los emigrantes de los campamentos mineros de origen aymaras, quienes vieron en las ciudades otras oportunidades laborales, espacios para abrir nuevas redes de mercados y obtener mayor acceso a demandas educacionales (Díaz, Galdames y Ruz, 2010). Iquique, para la década de 1970, fue un polo de atracción con la industria pesquera y posteriormente con la Zona Franca, generando una significativa migración desde las quebradas y cordillera andina hacia las ciudades a orillas del mar. De esta forma, las ciudades-puertos fueron el nuevo escenario donde los aymara buscaron oportunidades de diversa índole, dando inicio a un nuevo actor regional: los aymaras urbanos.

\section{COMENTARIOS}

Hasta fines del siglo XX prevaleció una noción peyorativa a la condición indígena, heredada desde la Colonia y más tarde asumida por los nuevos estados latinoamericanos en un contexto de construcción de las instituciones modernizantes y del Estado-Nación. Luego de un largo proceso de asimilación por parte de los nacientes estados, se desdibujó y desvalorizó la cultura de numerosos pueblos indígenas del continente. Las distintas políticas estatales implementadas tuvieron como fin incorporar a los pueblos originarios al carro del desarrollo, por la vía de la asimilación primero y la integración después. Si ello no ocurría, su desaparición sería un efecto natural del progreso. Lo que se consiguió, tras décadas de políticas hegemónicas, fue más pauperización, exclusión social, pérdidas culturales y, en algunos casos, desaparición de las sociedades indígenas. 
A partir de las últimas décadas ha existido un interés entre los investigadores nortinos por relevar la historia del otro, la del indígena, buscando visibilizar un retazo del pasado nacional olvidado. La sociedad aymara chilena fue uno de esos casos, subsumido en las acciones bélicas, económicas y estatales en el norte chileno; pero a diferencia de la tesis de la desintegración, no desaparecieron por la acción del Estado o la influencia de la cultura nacional. Como se diría hoy, se reinventaron y se mantuvieron más allá de las circunstancias históricas.

Como se ha constatado, el recorrido de la historia aymara está friccionada por la acción de los estados nacionales decimonónicos, por la Guerra del Pacífico, el ciclo salitrero, la chilenización y la acción del Estado chileno a través de la escuela fiscal, como hitos y procesos relevantes. En cada momento, los aymaras buscaron estrategias diversas que combinaron elementos de su cultura, agregaron unos y perdieron otros, como la lengua por la imposición del castellano. Migraron cuando fue necesario y crearon mundos duales de subsistencia, como fue la movilidad entre la salitrera y las chacras de los valles precordilleranos, cuando las circunstancias lo requirieron. Fueron arrieros y circularon a uno u otro lado de la frontera impuesta sobre su espacio cultural, como lo hacen hasta el día de hoy en las ferias fronterizas de Colchane o del Tripartido en las cercanías de Vísviri. Además, se incorporaron a las fiestas religiosas tradicionales y resemantizaron la ritualidad cuando fue necesario.

Recuperar la historia aymara regional implica todavía un largo camino. Un sendero pedregoso, puesto que las fuentes que nos informan sobre su pasado más reciente no los consignan ni tampoco los individualizan adecuadamente. Podríamos afirmar que fueron borrados bajo la etiqueta de la nacionalidad, de la ciudadanía y del campesinado. Por ello, profundizar en esta materia requiere de un esfuerzo multidisciplinario y colaborativo de distintas disciplinas sociales como la Sociología y la Antropología, que permitan rescatar la memoria aymara como parte de esa historia reciente. $\mathrm{Al}$ mismo tiempo, se requiere de una lectura crítica de las fuentes y de la búsqueda de nuevos archivos, como la literatura, la prensa o la memoria histórica concentrada en relatos, mitos, cánticos o tradiciones diversas.

\section{REFERENCIAS}

Aljovín de Losada, C. (1987). "Poderes locales en la primera mitad del XIX". Histórica XXI.1, 1-25.

Bonilla, H. (1988). "Comunidades indígenas y Estado nación en el Perú". En 
Comunidades campesinas. Cambios y permanencias (pp. 13-27). Chiclayo, Perú: Centro de Estudios Sociales Solidaridad.

Contreras, C. y Cueto, M. (2000). Historia del Perú contemporáneo. Lima, Perú: Instituto de Estudios Peruanos.

Díaz, A. (2003). "Sibaya. El pasado de una comunidad andina tarapaqueña. Siglos XVI-XIX”. Cuadernos de Trabajo 5 (Taller TINCU, Iquique).

(2009). "Los Andes de bronce. Conscripción militar de comuneros andinos y el surgimiento de las bandas de bronce en el norte de Chile". Historia No 42, vol. II, 371-399 (Pontificia Universidad Católica de Chile, Santiago).

Díaz, A. y Ruz, R. (2009). “Estado, escuela chilena y población andina en la ex subdelegación de Putre. Acciones y reacciones durante el período post guerra del pacífico (1883-1929)". Polis 24, 311-340.

Díaz, A., Galdames, L. y Ruz, R. (2010). Nación e identidad en los Andes indígenas de Arica y Estado chileno (1883-1929). Arica: Ediciones Universidad de Tarapacá.

Díaz, A., Mondaca, C. y Ruz, R. (2004) “"La administración chilena entre los aymaras: Resistencia y conflicto en los Andes de Arica (1901-1926)". Anthropológica 22, 215-235 (Pontificia Universidad Católica del Perú).

Díaz, A.; Ruz, R. y Galdames, R. (2011). "Participación de la población indígena en la política y justicia comunitaria en Arica y Tarapacá durante el siglo XIX". Revista de Estudios Histórico-Jurídicos 33, 511-532.

Dueñas, S. (2005). Efectos del Liberalismo decimonónico en la sociedad, población y bienes agrícolas indígenas. La comunidad de Tacna entre 1826 y 1864. Tesis de Magíster en Historia, Universidad de Chile, Santiago.

Galdames, L. y Díaz, A. (2007). "La construcción de la identidad ariqueña en las primeras décadas del siglo XX”. Diálogo Andino 29, 19-28 (Universidad de Tarapacá, Arica).

González, H. (2002). Los aymaras de la región de Tarapacá y el periodo republicano temprano (1821-1879). Santiago: Documento de Trabajo de la Comisión de Verdad Histórica y Nuevo Trato, Subgrupo Pueblo Aymara.

González, S. (1993). "Los aymaras de Isluga y Cariquima. Un contacto con la chilenización y la escuela". Revista de Ciencias Sociales 3, 3-10.

(2002a). Chilenizando a Tunupa. La escuela pública en el Tarapacá andino 1880-1990. Santiago, Chile: DIBAM (Dirección de Bibliotecas, Archivos y Museos).

(2002b). "La presencia indígena, boliviana y chilena en el enclave salitrero de Tarapacá. Una reflexión en torno a la fiesta de la Tirana". Si Somos Americanos. Revista de Estudios Transfronterizos 3, 121-146.

(2002c). Hombres y mujeres de la Pampa. Tarapacá en el ciclo de expansión del salitre. Santiago, Chile: Lom Ediciones.

(2004). El Dios cautivo. Las Ligas Patrióticas en la chilenización compulsiva de Tarapacá. Santiago, Chile: Lom Ediciones.

(2006). Arica y la triple frontera. Integración y conflicto entre Bolivia, Perú y Chile. Iquique, Chile: Aríbalo Editorial. 
Gundermann, H. (2001). Comunidad, sociedad andina y procesos socio-históricos en el norte de Chile. Tesis Doctoral, El Colegio de México, México. (2005). "Comunidad aymara y conflicto interno sobre la tierra en la Región de Tarapacá - Chile”. Cuadernos Interculturales 3(5): 43-66.

Sala i Vila, N. (1996). Y se armó el tole tole. Tributo indígena y movimientos sociales en el Virreinato del Perú, 1784-1814. Ayacucho, Perú: IEP José María Arguedas.

Thurner, M. (2003). “Los indios y las repúblicas entre 1830-1880”. En Historia de América Andina. Vol. 5: Creación de las repúblicas y formación de la nación. Quito, Ecuador: Universidad Andina Simón Bolívar.

Urquieta, D. (1993). De campesino a ciudadano. Aproximación jurídica. Cusco, Perú: Centro Bartolomé de Las Casas.

Van Kessel, J. (1992). Holocausto al progreso. Los aymaras de Tarapacá. La Paz, Bolivia: Hisbol.

Walker, C. (1999). De Tupác Amaru a Gamarra: Cuzco y la formación del Perú Republicano 1780-1840. Cusco, Perú: Centro de Estudios Regionales Andinos Bartolomé de Las Casas. 